J. Clin. Chem. Clin. Biochem.

Vol. 27, 1989, pp. $81-86$

(C) 1989 Walter de Gruyter \& Co.

Berlin - New York

\title{
A Practicable Two-Dimensional Electrophoretic Method for Routine Analysis of Urinary Proteins
}

\author{
By A. Lapin \\ Institut für Klinische Chemie und Laboratoriumsdiagnostik der Universität Wien
}

(Received October 1/December 5, 1988)

Summary: A two dimensional electrophoretic method is described for the routine clinical analysis of urinary proteins. Cellulose acetate electrophoresis is used for the first dimension, and SDS (sodium dodecyl sulphate) electrophoresis for the second dimension, the latter being performed together with gel staining (Coomassie Blue) on the "Phast System". The separation media are supplied as "ready-to-use" materials. The method is reliable and reproducible, and is complete within 100 minutes. The resulting two-dimensional pattern of major proteinuria contituents is evaluated visually from the distribution according to molecular weight (second dimension) and from the five zone pattern of cellulose acetate electrophoresis (first dimension). Certain "marker" proteins specific for certain pathological changes, as well as certain characteristic changes in protein spot constellation, can be more easily recognized and evaluated than in one-dimensional SDS electrophoresis.

\section{Introduction}

Using two dimensional electrophoresis, a combination of paper and starch gel electrophoresis, Butler and coworkers demonstrated in 1961 a high variability of the composition of proteins in pathological urinary samples (1). Eleven years later, Pesce, Boreisha and Pollak introduced a polyacrylamide SDS (sodium sodecyl sulphate) electrophoretic method for the separation of urinary proteins according to their molecular weights (2), which made it possible to differentiate between glomerular (high molecular weight) and tubular (low molecular weight) urinary proteins. In 1980 , Boesken developed a system for the classification of patterns obtained by SDS electrophoresis in relation to different aetiological aspects of proteinuria (3). He showed that renal as well as extrarenal disturbances can be reflected by changes in the proteinuric pattern. Other authors emphasized the importance of a reliable recognition, especially of proteins known to be markers for specific pathological changes. They proposed technical improvements of SDS electrophoresis, such as polychromatic silver staining (4), immunoblotting (5), and high resolution, two-dimensional electrophoresis $(6-8)$ for special purposes. The present paper describes a rapid method, suitable for routine conditions, for the separation of urinary proteins by two-dimensional electrophoresis. The first step of the separation (first dimension) corresponds to a routine cellulose acetate electrophoresis, while the second step, the SDS electrophoresis, is performed together with the final gel staining as an automatic procedure on the "PhastSystem". Urinary proteins are separated according to the five zone pattern of cellulose acetate electrophoresis as well as on the basis of their molecular weights. The resulting two-dimensional pattern of protein spots shows all the relevant urinary proteins, recognizable in most cases by their relative position. The resolution of the present method is higher than that of one-dimensional SDS electrophoresis alone. Due to a higher number of possible constellations of protein spots, the twodimensional pattern is more suitable for the characterization of numerous aetiological aspects influencing the composition of urinary proteins. 


\section{Materials and Methods}

Apparatus and Materials

The separation in the first dimension, by cellulose acetatc electrophoresis was done on a routine system from "CHEMETRON" (Milano, ltaly) using cellulose acetate film "Cellogel RS-100" with the non-barbiturate buffer "02A03-10, TRISGLYCINE SALICYLIC ACID" (pH 9,4).

The separation in the second dimension as well as the final gel staining was carried out on "PhastSystem TM" (Pharmacia Uppsala, Sweden). The SDS electrophoresis was performed on precast density gradient polyacrylamide gels "PhastGel Gradient 10-15" using "PhastGel SDS Buffer Strips". For the staining procedure "PhastBlue R tablets" (Coomassie Blue R 350) were used. Methanol, acetic acid and glycerol of analytical grade were supplied by Merck (Darmstadi, FRG).

For additional identification of proteins (immunofixation, immunochemical detection in blotting experiments) antisera supplied by Behring (Marburg, FRG) were used.

The immunofixation was performed with "Immunofixation Kit" provided by "CHEMETRON".

Total urinary protein was determined quantitatively by the Coomassie Blue method, using the kit from Bio-Rad (Munich, FRG).

\section{Procedure}

Only samples of fresh "four hour" urines were analysed by the present method. Separations in both dimensions were performed according the standard protocols recommended by manufacturers, with the following modifications. Application of the urinary sample to the surface of "Cellogel" was repeated ten times, in order to concentrate the analysed proteins. The best results were obtained when a voltage of $20 \mathrm{~V}$ was applied during the whole application procedure. After each application the "drop" of sample was dried (by mouth blowing). It was advantageous to stain the sample with bromphenol blue before application.

The separation by cellulose acetate electrophoresis was than performed at $260 \mathrm{~V}$ for $25 \mathrm{~min}$. During this time the total separation distance reached $30 \mathrm{~mm}$. Thereafter, a $3 \times 30 \mathrm{~mm}$ strip corresponding to the sample separation was cut out with a scalpel. The "Cellogel" strip was then transferred with philatelic tweezers to the "PhastSystem" and overlayed onto the "stacking gel area" of the "PhastGel Gradient 10-15", which was already in the apparatus. The separation was then done at $300 \mathrm{~V}, 5^{\circ} \mathrm{C}$ and for $80 \mathrm{Vh}$.

Thereafter, the "PhastGel Gradient 10-15" was transferred to the development unit of the "PhastSystem" and stained according to the application file No. 200. Ready gel was photocopied with "zoom" enlargement of $141 \%$ for documentation.

\section{Identification of spots}

The main urinary proteins separated as spots on the twodimensional pattern were identified by:

1. their known mobilities within the five zone pattern of cellulose acetate electrophoresis (verified by immunofixation) $(9,10)$.

2. their known molecular weights $(11,12)$ and

3. as reported earlier by mobilities within the pattern of SDS electrophoresis $(5,13)$.

The definitive identification of proteins listed on figure 1, was confirmed by blotting experiments. For this purpose the thermal diffusion blotting (PhastSystem Application file No. 220) and immunochemical detection on the nitrocellulose membrane (5) were used.

\section{Results}

Figure 1 outlines the two-dimensional pattern of proteins found in pathological urinary samples. The first dimension (horizontal axis) represents the five zone separation by cellulose acetate electrophoresis known from serum electrophoresis. albumin, $\alpha_{1^{-}}, \alpha_{2^{-}}, \beta$ - and $\gamma$-globulins. The second dimension (yertical axis) represents the separation by SDS electrophoresis, where the distribution of proteins follows the logarithm of molecular weight ranging from 10 to $250 \cdot 10^{3}$.

In cases of dysfunction of the glomerulo-tubular apparatus, spots situated in the upper half of the pattern correspond to proteins of glomerular origin, while spots in the lower part are relevant to tubular dysfunction.

The glomerular selectivity is characterized by the relative abundancies of spots corresponding to IgG, transferrin and albumin and they can be estimated by their visual comparison, as proposed for evaluation of one-dimensional SDS electrophoresis by Boesken's classification (3). Moreover, the better resolution and recognition of urinary proteins in the two-dimensional pattern permits the identification of further pathogenetic aspects of proteinuria as demonstrated by following examples:

Figure 2 and 3 show two proteinuric patterns of tubular proteinuria. In both pictures, protein spots are situated in the lower part of the pattern. The albumin spots are of comparable intensity in both cases. The first pattern (fig. 2) contains 6 spots, whereas the second (fig. 3) shows identical but more intense spots, and several additional low molecular proteins $(\rightarrow)$. The first proteinuric pattern (fig. 2) was obtained from a 30-year-old woman, 10 days after an intoxication by sodium chlorate. As reported (14), this substance causes tubular injuries. At the time of the analysis the kidney function was improved (serum creatinine $130 \mu \mathrm{mol} / \mathrm{l})$. It can be assumed that the mild proteinuria (total concentration of proteins in urine $0.4 \mathrm{~g} / \mathrm{l}$ ) is an expression of residual functional damage of the tubular apparatus. The second pattern (fig. 3) shows proteins in the urine of a 41 -year-old man with a terminal kidney insufficiency caused by a chronic abuse of analgesics. The total concentration of urinary proteins was $0.9 \mathrm{~g} / \mathrm{l}$, the serum creatinine $760 \mu \mathrm{mol} / \mathrm{l}$. The patient was submitted to chronic haemodialysis. The proteinuric pattern can be considered to show pronounced tubulointerstitial damage with low molecular weight proteins arising from the tissue degradation.

The next two pictures show proteinuric patterns due to different glomerular disorders. The first case (fig. 4) was a peracute glomerulonephritis followed by 


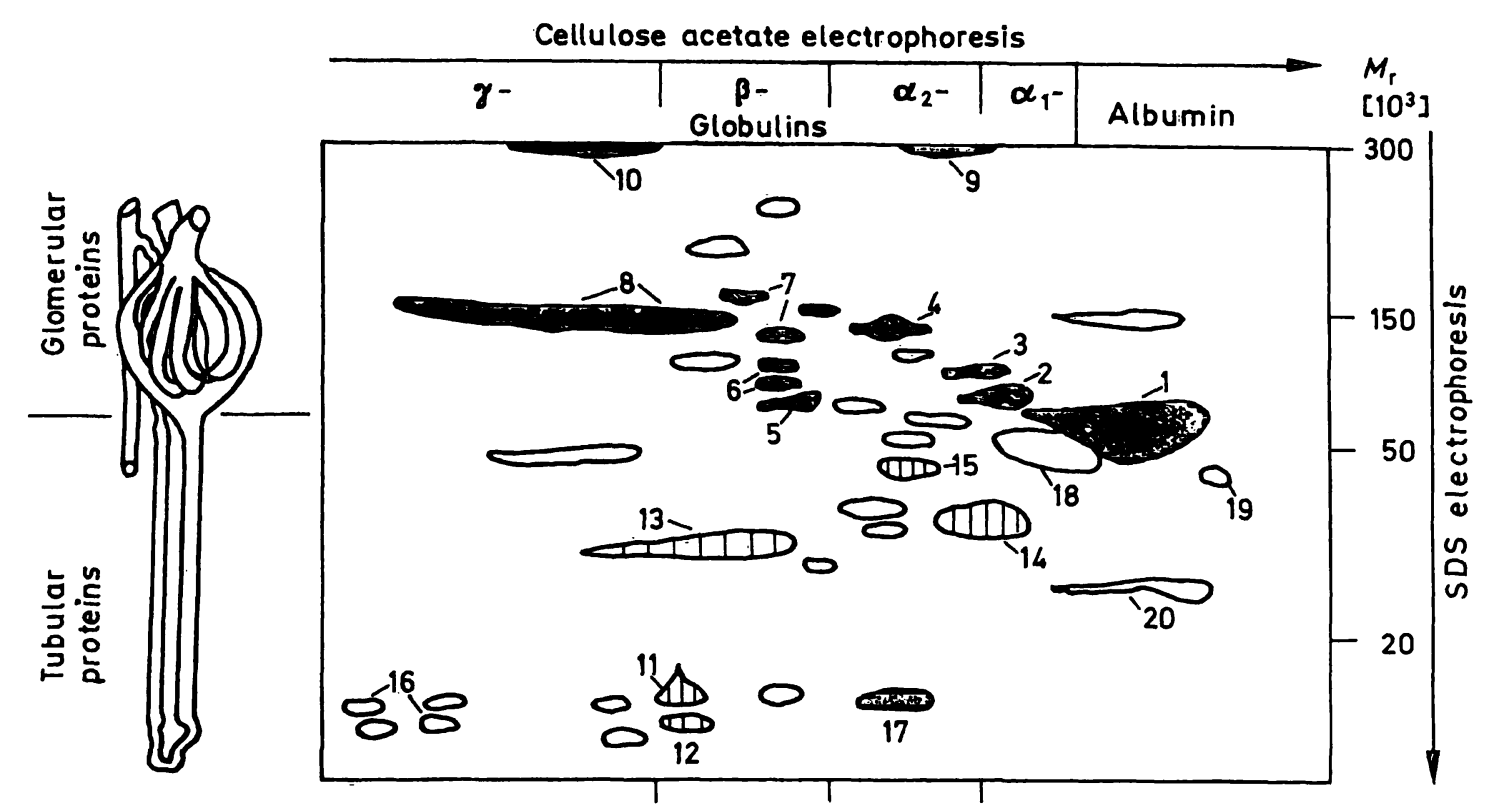

Fig. 1. Schematic map of proteins found in different pathological samples. Horizontal axis (1st dimension) cellulose acetate electrophoresis. Vertical axis (2nd dimension) SDS electrophoresis.

Glomerular proteins: 1 albumin, $2 \alpha_{1}$-proteinase inhibitor, $3 \alpha_{1}$-antichymotrypsin, 4 inter- $\alpha$-trypsin inhibitor, 5 haemopexin, 6 transferrin, 7 C-3 complement, 8 IgG and IgA (monomer), $9 \alpha_{2}$-macroglobulin, 10 IgM.

Tubular proteins: 11 retinol binding protein, $12 \beta_{2}$-micro globulin, 13 light chains of immunoglobulins, $14 \alpha_{1}$-microglobulin, $15 \mathrm{Zn}-\alpha_{2}$-glyco protein, 16 lysozyme and post- $\gamma$-globulin.

Other proteins: 17 haemoglobin (monomer), 18 orosomucoid ( $\alpha_{2}$-acid-glycoprotein), 19 prealbumin, 20 apolipoprotein AI.

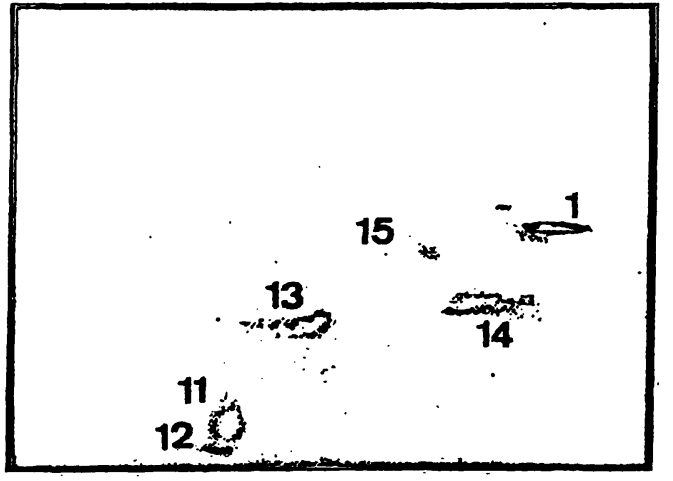

Fig. 2. Urinary proteins from a patient 10 days after her intoxication by sodium chlorate. Residual functional tubular damage.

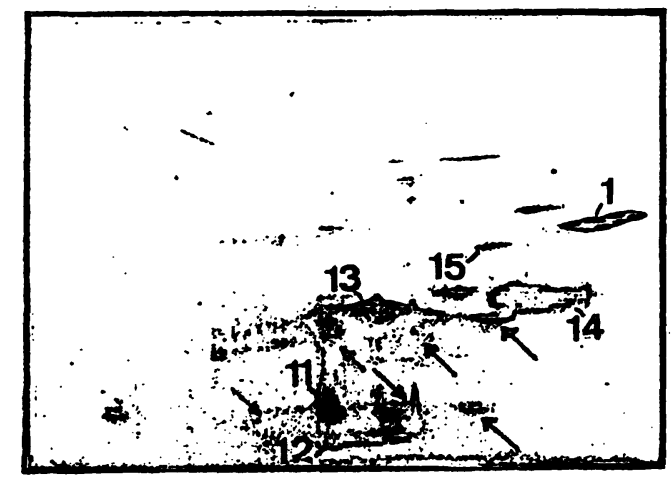

Fig. 3. Urinary proteins from a patient with chronic abuse of analgesics. Pronounced tubulo-interstitial damage with a degenerative process. Tubular proteins as reported in figure 2 with additional low molecular weight proteins from proteolytic degradation $(\rightarrow)$.

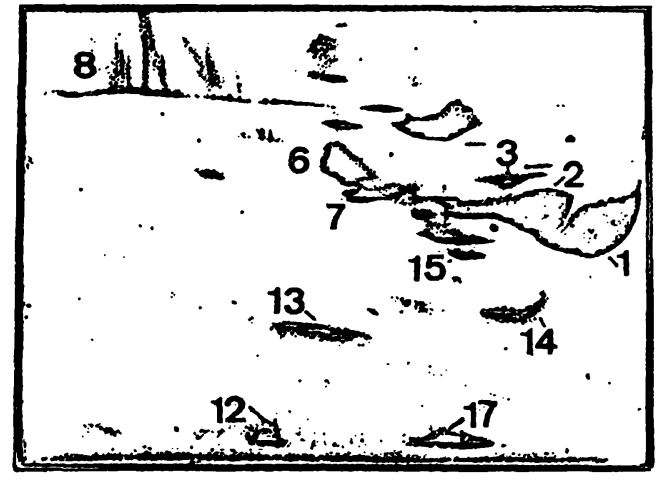

Fig. 4. Urinary proteins from a patient suffering from a peracute glomerulonephritis.

$\therefore$ Acute phase of inflammation is marked by proteins of $\alpha_{1}$ - and $\alpha_{2}$-zones such as $\alpha_{1}$-proteinase inhibitor (showing about the same intensity as albumin).

- Non selective glomerular proteinuria is indicated by proteins of high or very high molecular weights (immunoglobulin area) [8].

- Massive haematuria marked by haemoglobin monomer [17].

- Tubular proteinuria can be characterized as secondary-functional.

kidney failure in a 38-year-old male patient. The serum creatinine was higher than $1000 \mu \mathrm{mol} / \mathrm{l}$ and the total concentration of urinary proteins $9.8 \mathrm{~g} / \mathrm{l}$. The extraordinarily impressive clinical state of the patient were well confirmed by the proteinuric pattern: the picture is dominated by extensive spots of albumin and $\alpha_{1}$-proteinase inhibitor, as well as by other "glo- 
merular" and acute phase proteins. The "line" of immunoglobulins $\operatorname{IgG}$ shows vertical streaks due to overloading artifacts. On the bottom of the picture in the $\alpha_{2}$-zone is a spot corresponding to haemoglobin monomer, confirming a haematuria. In contrast, "tubular" proteins are present only with average intensity and their constellation is comparable to the "functional tubular proteinuria" showed on figure 2.

Figure 5 shows another glomerular proteinuria from a 69-year-old woman suffering from focal-segmental sclerosing glomerulo-nephritis as revealed by biopsy. The total concentration of proteins in urine was 1.1 $\mathrm{g} / \mathrm{l}$ and serum creatinine $133 \mu \mathrm{mol} / \mathrm{l}$. The main proportion of urinary proteins is represented by albumin [1]. Other "glomerular" proteins are present in rather low amounts. No "tubular" proteins can be seen.

Using the present method, some unusual findings were obtained. The protein pattern shown on figure 6 was found in the urine from a 37-year-old male patient suffering from a non-renal infection with body temperature $38.5^{\circ} \mathrm{C}$ and white blood cells $15 \times 10^{3}$. The serum creatinine was within the normal range, 90 $\mu \mathrm{mol} / \mathrm{l}$, and the total urinary protein $(0.6 \mathrm{~g} / \mathrm{l})$ was

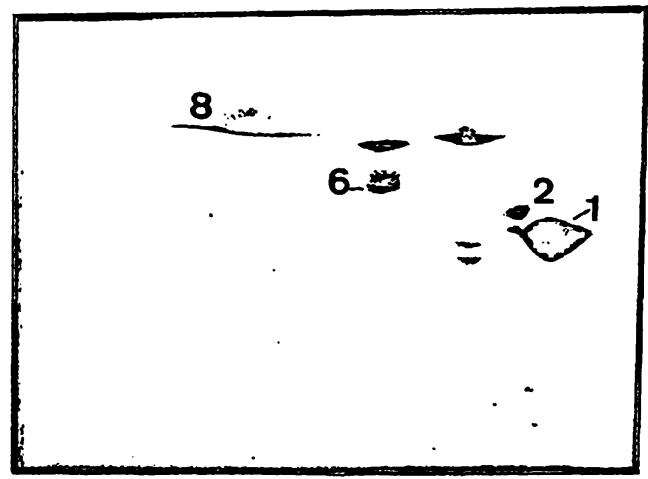

Fig. 5. Urinary proteins from a patient suffering from a chronic, focal sclerosing, segmental glomerulonephritis. Glomerular selective proteinuria. Main proportion of urinary proteins $(80 \%)$ is represented by albumin [1].

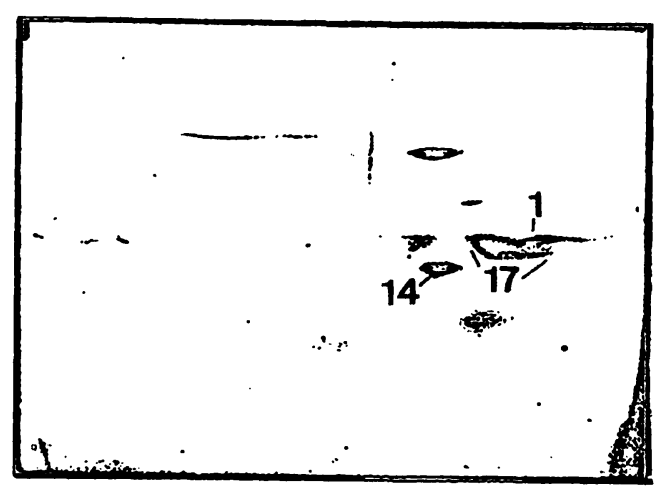

Fig. 6. Urinary proteins from a patient suffering from a nonrenal, febrile infection.

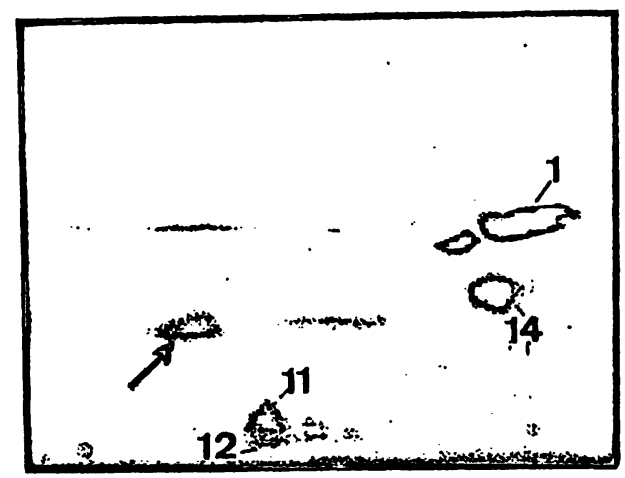

Fig. 7. Tubular proteinuria with monoclonal paraprotein of type kappa free light chain $(\rightarrow)$.

apparently due to the fever accompanying proteinuria (15). The protein pattern can be characterized neither as glomerular nor as tubular. The albumin is represented by a thin spot and is surrounded by a spot corresponding to orosomucoid ( $\alpha_{1}$-acid glycoprotein) [17]. According to Edwards and coworkers (8), "the increases in concentration of orosomucoid in serum and (presumably) urine suggest disorders involving leukocyte proliferation".

Another occasional finding is presented on figure 7. A 61-year-old man showed a progressive kidney failure. At the time of the analysis the serum creatinine was $220 \mu \mathrm{mol} / \mathrm{l}$ and total urinary protein $0.6 \mathrm{~g} / \mathrm{l}$. Urinary proteins show a tubular pattern comparable to the case shown on figure 2. However, an additional spot was found $(\rightarrow)$ which was identified by subsequent immunofixation as a monoclonal paraprotein of type "kappa free chain".

\section{Discussion}

The aim of this work was to develop a simple, fast and reliable method for clinical analysis of proteins in pathological urinary samples. As a combination of two electrophoretic separations, the present method shows a better resolution than SDS electrophoresis alone. In comparison with the conventional high resolution electrophoresis, the use of cellulose acetate electrophoresis for the first dimension instead of isoelectric focusing results in somewhat lower resolution. However there are several advantages: The cellulose acetate electrophoresis requires less time and less experience as compared with isoelectric focusing. Problems arising from the use of ampholytes, especially their interference with the gel of the second dimension (16) are avoided. Using the cellulose acetate electrophoresis, the high salt content of the sample can be better compensated, and this in turn permits the con- 
centration of the investigated proteins by repeated application of the urinary sample. The "paper-like" consistency of "Cellogel" facilitates the transfer from the 1 st to 2 nd dimension. The second dimension, the SDS electrophoresis, as well as gel staining are performed automatically on "PhastSystem". Moreover, all separation media are provided as "ready-to-use" with quality warranted by the manufacturers. Selfpreparation of gels of their pretreatment or preincubation during the procedure is unnecessary. Therefore, the present method is less laborious than other comparable two-dimensional electrophoretic methods performed on a "micro scale" $(13,16-19)$.

With the exception of the application of the sample and its transfer from the first to the second dimension, no special manual skill is needed, so that the total analysis requires only 100 minutes. The method shows good reproducibility, as shown by the fact that the analysis of diluted control serum on 20 consecutive days always revealed the same protein pattern, verified by visual comparison of the resulting gels.

For gel staining, the Coomassie Blue R-350 method was preferred to the silver stain procedure. This was decided in view of better practicability and reliability, since the silver stain requires generally more technical experience, as well as reagents of high quality (especially the water). Moreover, the Coomassie Blue $\mathrm{R}$ procedure only reveals urinary proteins when they are present in pathological concentrations. Samples from healthy persons with total urinary protein below 0.15 $\mathrm{g} / \mathrm{l}$ show just a small spot of albumin. Since neither urea nor reducing reagents are used, the urinary proteins separated by the present method remained in their native unchanged form, so that the resulting two-dimensional pattern can be considered as a "descriptive picture" of urinary proteins.

The distribution of urinary proteins according to the five zones of cellulose acetate electrophoresis represents a familiar system in clinical chemistry. In the same way the molecular weight distribution represents a comprehensive criterion.

\section{References}

1. Butler, E. A., Flynn, F. V., Harris, H. \& Robson, E. B. (1961) Clin. Chim. Acta 7, 34-41.

2. Pesce, A. J., Boreisha, I. B. \& Pollak, V. R. (1972) Clin. Chim. Acta 40, 27-34.

3. Boesken, W. $\dot{H}$. (1981) In: Electrophoresis' 81 (Allen, R. C. \& Arnaud, P., eds.) Walter de Gruyter \& Co., Berlin, New York, pp. 453-462.

4. Wurster, U., Krull, F. \& Ehrich, J. H. H. (1984) In: Electrophoresis' 84 (Neuhoff, V., ed.) Vlg. Chemie, Weinheim, Deerfield Beach, Basel, pp. 446-448.
Thus, the two-dimensional protein pattern is evaluated visually by following steps:

(i) the evaluation of distribution of proteins revealed by both steps of separation:

- five zone pattern of cellulose acetate electrophoresis

- molecular weight distribution revealed by SDS electrophoresis

(ii) recognition of "marker" proteins by their relative positions on the two-dimensional pattern and estimation of their diagnostic significance for specific pathological changes.

(iii) evaluation of protein spot constellation; differentiation between patterns typical for certain disorders and irregular or supplemental spots.

Especially the last step (iii) permits diagnoses that could not be achieved by one-dimensional SDS electrophoresis alone. Thus, the proposed diagnostic procedure permits a deductive evaluation of two-dimensional protein patterns. For instance, as shown on figure 2, 3 and 4, in all three cases the excretion of low molecular weight proteins into the urine was observed. However, the consideration of this "tubular proteinuria" in the context of each individual pattern of all urinary proteins, produces three different diagnoses:

figure 2: residual functional tubular damage

figure 3: degenerative process of kidney tissue and functional, tubular dysfunction

figure 4: secondary tubular proteinuria, due to overloading of tubular reabsorption capacity (22).

The high variability of urinary proteins, which can be revealed and evaluated by the present method, requires a further systematic study in relation with anaminestic, clinical and especially patho-morphologic findings.

The present method represents a further improvement in the routine analysis of urinary proteins, and it can serve as a non-invasive diagnostic method in nephrology.

5. Perini, J. M., Dehon, B., Marianne, T., Foulard, M. \& Roussel, Ph. (1987) Clin. Chim. Acta 169, 255-266.

6. Anderson, N. G., Anderson, N. L. \& Tollaksen, S. L. (1979) Clin. Chem. 25, 1199-1210.

7. Edwards, J. J., Anderson, N. G., Tollakson, S. L., von Eschenbach, A. C. \& Guevara, J. G. jr. (1982) Clin. Chem. 28, 160-1.63.

8. Edwards, J. J., Tollaksen, S. L. \& Anderson, N. G. (1982) Clin. Chem. 28, 940-948. 
9. Laurell, C. B. (1972) Scand. J. Clin. Lab. Invest. 29 (Suppl. 124), $71-82$.

10. Agguzzi, F., Poggi, N. \& Chiara, T. (1978) La Ricerca Clin. Lab. 8 (Suppl. 1) $171-177$.

11. Putnam, F. W. (1975) In: The Plasma Proteins, Vol. I/2 (Putnam, F. W., ed.) Academic Press, New York, San Francisco, London: pp. 57-131.

12. Heide, K., Haupl, H. \& Schwick, H. G. (1977) In: The Plasma Proteins, Vol. III/8 (Putnam, F. W., ed.) Academic Press, New York, San Francisco, London, pp. 545-597.

13. Longberg-Holm, K., Bagley, A., Nussbacher, J. \& Heal, J. M. (1982) Clin. Chem. 28, 962-968.

14. Oliver, J. J., Smith, H. \& Watson, A. A. (1972) J. Forensic. Sci. Soc. $12,445-448$.

15. Sandberg, T., Cooper, E. H., Lidin-Janson, G. \& Yu, H. (1985) Nephron 4l, 39-44.
16. Cheong (Kim), K. S., Arold, N. \& Neuhoff, V. (1986) In: Electrophoresis' 86 (Proceedings of 6th discussion meeting in Munich, 27. -29 th Oct. 1986), (Radola, B. J., ed.) pp. $223-228$.

17. Felgenhauer, K. \& Hagedorn, D. (1980) Clin. Chim. Acta $100,121-132$.

18. Marshall, T. (1983) Clin. Chem. 29, 592-593.

19. Hochștrasser, D., Augsburger, V., Pun, Th., Weber, D., Pellegrini, Ch. \& Muller, A. F. (1988) Clin. Chem. 34, 166170.

20. Yu, H., Yanagisawa, Y., Forbes, M. A., Cooper, E. H., Crockson, R. A. \& Mac Lennan, I. C. M. (1983) J. Clin. Pathol. 36, 253-259.

21. Schiwara, H. W., Hebell, T. \& Dräger, H. (1988) Fresenius Z. Anal. Chem. 330, 427.

22. Bernhard, A., Viau, C., Ouled, A. \& Lauwerys, R. (1987) Nephron 45, 115-118.

DDr. Alexander Lapin

Institut für Klinische Chemie und Laboratoriumsdiagnostik der Universität Wien

Lazarettgasse 14

A-1090 Wien 